\title{
Care Technologies in Nursing for People with Colorectal Neoplasia: Integrative Review
}

\author{
Aryele Rayana Antunes de Araújo, Alexsandra Rodrigues Feijão, \\ Lays Pinheiro de Medeiros, Mayra Beatriz Costa Medeiros, Annanda Luyza Carias Maia, \\ Ana Luiza Brandão de Carvalho Lira, Isabelle Katherinne Fernandes Costa Assunção \\ Department of Nursing, Health Science Center, Federal University of Rio Grande do Norte (UFRN), Central \\ Campus, Natal, Brazil \\ Email: isabellekfc@yahoo.com.br
}

Received 3 June 2016; accepted 27 August 2016; published 30 August 2016

Copyright (C) 2016 by authors and Scientific Research Publishing Inc.

This work is licensed under the Creative Commons Attribution International License (CC BY). http://creativecommons.org/licenses/by/4.0/

(c) (i) Open Access

\begin{abstract}
Objective: Identifying in the literature the care technologies used by nurses for people with colorectal neoplasia on Nietzsche's conceptual perspective. Method: It consists in an integrative review of the literature held in the database: Latin-American Literature and Caribbean in medical health sciences Literature Analysis and Retrieval System Online, Database in Nursing, US National Library of Medicine, Cumulative Index to Nursing \& Allied Health Literature, Scopus Info Site and Web of Science in December 2015. Results: 28 articles were selected to compose the final sample of this review, which were analyzed and categorized in management technology $(86.20 \%)$, assistance technology $(20.68 \%)$ and educational technology $(10.34 \%)$. Studies published in the last five years have predominated $(62.06 \%)$, in international territory $(82.75 \%)$ and with evidence level IV (44.82\%). Conclusion: Today the growth on the production about this theme has been highlighted, but there is an important discrepancy between the researches with high and low level of scientific evidence, showing the need of more studies about technologies that strengthen the experience of nursing.
\end{abstract}

\section{Keywords}

Nursing, Colorectal Neoplasia, Technology, Oncological Nursing

\section{Introduction}

Nursing has achieved, in the last decades, a growth and transformation of its work process. This way, it led to an

How to cite this paper: de Araújo, A.R.A., Feijão, A.R., de Medeiros, L.P., Medeiros, M.B.C., Maia, A.L.C., de Carvalho Lira, A.L.B. and Assunção, I.K.F.C. (2016) Care Technologies in Nursing for People with Colorectal Neoplasia: Integrative Review. Open Journal of Nursing, 6, 610-619. http://dx.doi.org/10.4236/ojn.2016.68065 
incorporation of new technologies and expansion of the possibilities on the fields of work. This process is complex and leads to new demands for the job, that generates the need of constant theoretical-practical update on the part of the nurses [1].

Working with nursing involves the constant use of technologies from the specific knowledge of the profession. Such technologies are a result of a process made from the daily experience and results of researches, seeking the development of scientific expertise to the idealization of material products, or not, that generates interventions in a determined practical situation [1] [2].

According to Nietzsche, the concept of Technology is understood as a result of implemented cases from the daily experience and research, to the development of a scientific knowledge set for the creation of material products, or not, with the goal to provoke interventions on a determined practical situation. All this process must be systematically evaluated and controlled [3].

Care technologies are classified by Nietzsche in educational: "systematic set of scientific expertise that make it possible the planning, execution, control and monitoring involving all the educational process", assistance: "construction of a technical-scientific knowledge that is a result of investigations, application of theories and the daily experience of the professional and the clientele, constituting, therefore, in a set of systematic, processual and instrumental actions to the delivery of a qualified assistance to the human being in all dimensions"; and, finally, managerial: "systematic process and documented theoretical-practical actions (planning, execution and evaluation), used in the management of the assistance and health services, to intervene on the professional practical context, seeking an improvement of its quality" [3].

According to global estimates, the colorectal cancer is the third most common type among men, and the second among women, being those the ones that affect some portion of the large intestine and the rectum. In Brazil, it is estimated that between 2016 and 2017 it will appear approximately 34,280 thousands new cases of this type of cancer.

Among the risk factors to the development of this tumor stand out the age above 50 years, familial history, obesity, low consumption of calcium, sedentary lifestyle, inadequate food habits, especially the excessive consumption of meat, and inflammatory diseases of the intestine [4] [5].

The treatment of colorectal cancer encompasses chemotherapy and/or surgery and brings consequences to the psychological, social and physical domains of the individual, in addition to affecting his quality of life due to changes on the lifestyle, the confrontation of the stigma around the cancer. These are factors which require from the nursing a specialized care to this clientele [6] [7].

In this meantime, it's indispensable that the nursing develops proper technologies directed to the individual with colorectal cancer that approach all the complexity of the care that he needs since the diagnostic of the disease, passing through all his treatment, until the post-treatment interventions [8] [9].

From what is exposed, the objective of this study was to identify in the literature the care technologies used by nurses, from the Nietzsche's theoretical reference to people with colorectal neoplasia [2].

\section{Methodology}

It consists in an integrative review of the literature, method that makes it possible a broad understanding about a determined subject and to identify the gaps of knowledge [10]. As the guiding question the study had: "What are the nursing technologies used in the care of people with colorectal neoplasia?”

To carry out this research, the following stages were made: identification of the problem, establishment of conditions to inclusion and exclusion of studies (sample selection), definition of the data that will be acquired from the selected studies, analysis of the selected studies, interpretation of the results and display of the review [11].

The data gathering was performed during the month of January 2016, covering articles in complete text format. The inclusion condition taken was: electronically complete available articles, about the studied theme; Portuguese, Spanish and English published articles. The excluded ones were editorials, reflection articles, letters, opinion articles, book chapters, theses, dissertations, sneak preview notes and manuals.

The search was made based on the following database: Latin-American and Caribbean in medical health sciences Literature (LILACS) Medical Literature Analysis and Retrieval System Online (Medline), database on nursing (BDENF), US National Library of Medicine (PUBMED), Cumulative Index to Nursing \& Allied Health Literature (CINAHL), Scopus Info Site (SCOPUS) and Web of Science, using Desc/MeSH descriptors. Chart 1 quantitatively details the steps of the study to acquire the final sample. 
Chart 1. Strategy of search and number of articles found in the database.

\begin{tabular}{ccc}
\hline Database & Strategy of Search & $\begin{array}{c}\text { Found } \\
\text { Articles }\end{array}$ \\
\hline LILACS & (Colorectal neoplasia) AND (tw: ((“Nursing Care” OR “Oncological Nursing”))) & 11 \\
MEDLINE & (Colorectal neoplasia) AND (tw: ((“Nursing Care” OR “Oncological Nursing”))) & 47 \\
BDENF & (Colorectal neoplasia) AND (tw: ((“Nursing Care” OR “Oncological Nursing”))) & 3 \\
PUBMED & (Colorectal neoplasia) AND (tw: ((“Nursing Care” OR “Oncological Nursing”))) & 12 \\
CINAHL & (Colorectal neoplasia) AND (tw: ((“Nursing Care” OR “Oncological Nursing”))) & 34 \\
SCOPUS & (Colorectal neoplasia) AND ((“nursing care” OR “oncological nursing”)) AND (LIMIT-TO & 99 \\
Web of Science & (SUBJAREA, “NURS”)) AND (LIMIT-TO (SRCTYPE, “j”)) & 0 \\
\hline
\end{tabular}

Source: Data from the research, 2016.

The search on the database was performed separately, by two researchers, being the disagreements between the results solved by common understanding among them.

To the selection of the studies, the PRISMA recommendations were used as shown in Figure 1 [12]. During the data collection there were excluded studies because they did not gave the proper answer to the guiding question and the ones duplicated in the database were also excluded.

During the evaluation and categorization of the studies, the authors created an instrument, to obtain the information of the studies. This had: identification of the articles, objectives of the study, methodological design, participants, results, difficulties/limitations, conclusions and implications to the Nursing pointed out by the researchers, and the technology in Nursing used.

To analyze the level of evidence, the Institute Joanna Briggs parameter was used, which classifies the studies in four levels of scientific evidence, being: "Level I: Randomized evidence; Level II: Evidence obtained from at least one controlled randomized clinical trial; Level III.1: Evidence obtained from well-planned controlled clinical trials, without randomization; Level III.2: Evidence obtained from well-planned cohort studies or case-control, analytical studies, preferably of one more center or research group; Level III.3: Evidence obtained from multiple temporal series, with or without intervention and dramatic results in non-controlled experiments; Level IV: Statement of respected authorities, based on the clinical conditions and experience, descriptive studies or reports of a committee of experts [13].

The descriptive presentation was chosen along with its discussions, seeking a better appreciation.

\section{Results and Discussion}

Among the 28 selected articles to the sample that had technologies about the care in nursing, 10 were selected in the database MEDLINE, 5 in the LILACS, nine in the CINAHL and four in the PUBMED.

About the year of publication, it's possible to see that most of the publications were between 2011 and 2015 (62.06\%). It's possible to see that most of the analyzed studies (82.75\%) were published in international journals and $57.1 \%$ in journal of the Nursing field.

Although there were studies found in Brazil (17.5\%), being those in the South and Southwest regions of the country, the studies included countries of the American, Asiatic, European and Oceania continents, reflex of the globalization of the disease and relevance in its study.

About the level of evidence, $44.82 \%$ of the studies, being descriptive studies or with a qualitative approach, were classified with level IV; $24.13 \%$ for representing the well-planned cohort studies or case-control, and analytical studies were classified with level of evidence III.2. And 20.68\% as it's about randomized clinical trials were classified with level of evidence II [14].

The results of the studies were grouped in three categories based on the approached technology. Most of the studies (86.20\%) were about the management technologies; followed by the researches that were about the assistance technologies (20.68\%); and just three articles (10.34\%) came as a result of researchin the educational care technologies.

It's important to highlight that one technology can be used to the analysis or improvement of another 


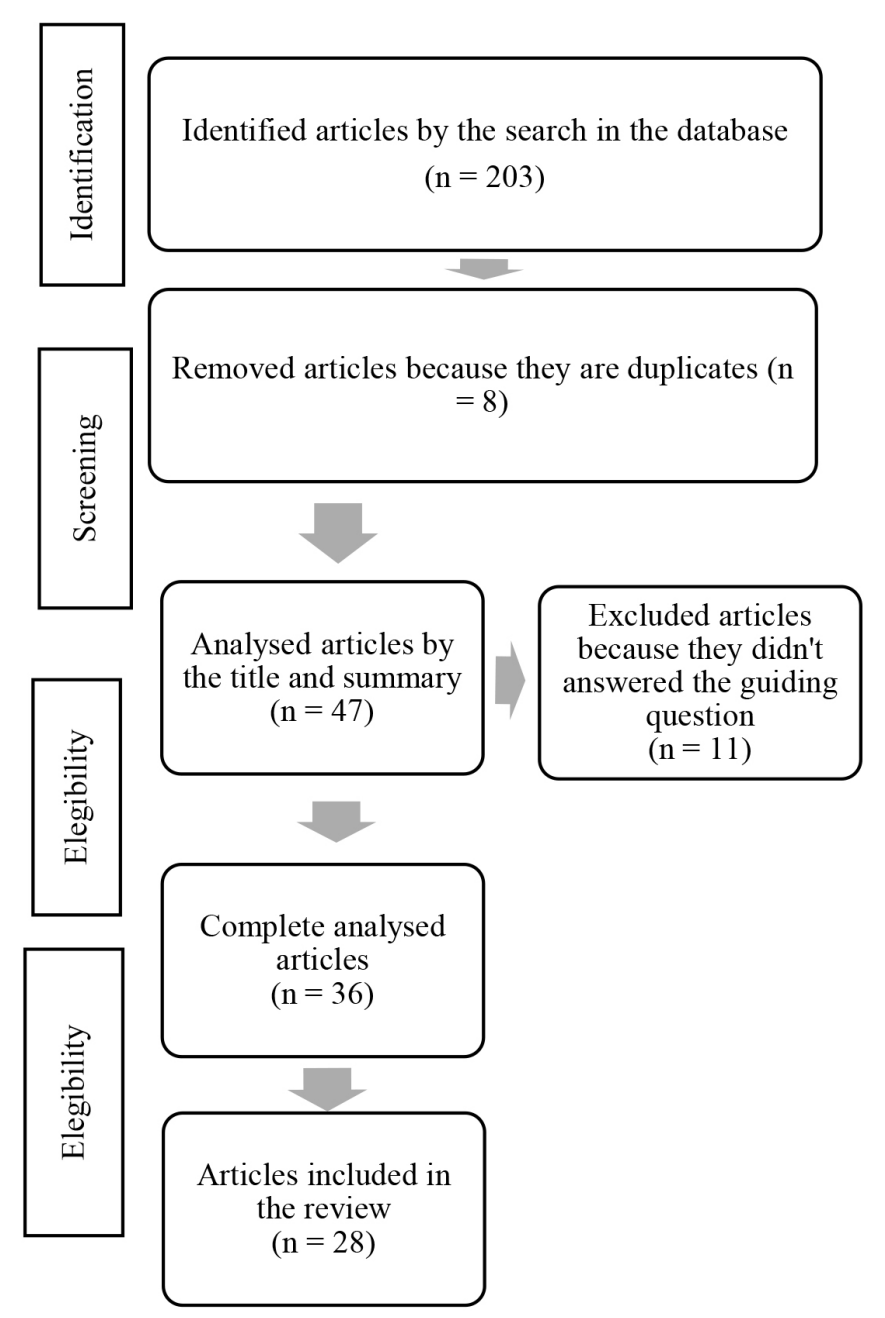

Figure 1. Flowchart of the selection of the articles for the integrative review of the literature, made from the PRISMA recommendations [12].

technology and they complement each other. The analysis of the technologies was made considering the planning of the studies and their results, which are shown in Table 1.

Technologies are taken as a "set of systematized theoretical-practical actions used on the management of the care and health services" [1] [2]. The studies that approached this kind of technology investigated the ways of evaluation of the care, the perception of the individuals about the disease, the health services and other aspects to generate information that led to an improvement to the care and the services performed for them.

Five studies measured the quality of life of the patient with colorectal cancer, some approaching the treatment or the specific outcome of the disease, with the goal of planning and management of the assistance performed to the patients in a way to increase their quality of life, in addition to promote better post advising [14]-[17].

Studies about the quality of life are becoming common between the nurses all around the world and it's because most part of the clients assisted by the nursing team suffers from chronical affections or long treatment, where the cure is not always a possibility, but a healthy quality of life must be sought and developed. Nurses of Hong Kong highlight studies of this kind, which map the degrees of quality of life, help the professionals to identify people at risk of suffering a reduction on the quality of life and projection and also to plan interventions of appropriate care to improve their quality of life [18].

In addition, one of the main surgical treatments of colorectal neoplasia is undergoing an intestinal ostomy, a procedure that brings countless physical and psychological consequences, like a shift in the elimination of stool, body image disorder, sexual dysfunction, depression, social isolation, among other factors that affect directly on 
Table 1. Distribution of the studies in relation to the management technologies used on the care of the people with colorectal neoplasia.

\begin{tabular}{|c|c|}
\hline ID & Used Technology \\
\hline $\begin{array}{l}\text { A.M. O’MARA AND A.M. } \\
\text { DENICOFF. } 2010\end{array}$ & $\begin{array}{l}\text { Measurement of the quality of life of the people with colorectal neoplasia used to plan and manage the } \\
\text { health assistance. }\end{array}$ \\
\hline K. BEAVER ET AL. 2011 & Evaluation of the satisfaction of the clients with colorectal neoplasia from tracking over telephone. \\
\hline B. MCCARTHY. 2014 & $\begin{array}{l}\text { Exploration of the perception of the people with colorectal neoplasia and their relatives, about their relation } \\
\text { with the health professionals that rendered assistance during the chemotherapeutic treatment. }\end{array}$ \\
\hline $\begin{array}{l}\text { A. S. ANDERSON ET } \\
\text { AL.2013 }\end{array}$ & $\begin{array}{l}\text { Evaluation of the knowledge of medics and nurses about the risks and benefits of the weight management } \\
\text { in patients with colorectal neoplasia to identify the barriers noticed when giving advices about the life style } \\
\text { of those clients. }\end{array}$ \\
\hline SIERKO, E. ET AL. 2011 & $\begin{array}{l}\text { Identification of the physical, psychological and social needs of the patients with colorectal neoplasia with } \\
\text { an advanced diagnostic of the disease. }\end{array}$ \\
\hline
\end{tabular}

JONSSON ET AL. 2011 Description of the immediate post-surgery experience after the operation of colorectal neoplasia.

MAHTICONA

BENAVENTE SB,

SANTOS MONTEIRO EM, SIQUEIRA COSTA AL. 2015

FAUL ET AL. 2012

Evaluation of thesocio-cultural and genderfactors in the Afro-American population in relation to the decision about the tracking of the colorectal neoplasia.

M. G. A. NORWOOD ET

AL. 2011

Evaluation of the benefits of the assistance plans to the survivors of colorectal neoplasia.

BUETTO LS, ZAGO MMF. Interpretation of the meanings attributed to the quality of life of patients with colorectal neoplasia in 2015

UCHIMURA TT. 2008

MICHELONE APC, SANTOS VLCG. 2004

TICONA BENAVENTE

SB, SANTOS MONTEIRO

EM, SIQUEIRA COSTA

AL. 2015

CHAVES PL, GORINI

MIPC. 2011

GROCOTT, P ET AL. 2001

PART. 1

GROCOTT, P ET AL. 2001

PART. 2

C.J.H. VAN DE VELDE ET

AL. 2013

C.J.H. VAN DE VELDE ET AL. 2014

Comparison of the costs and labor needs of the Nursing on the open surgical and laparoscopic approaches on the treatment of colorectal neoplasia. chemotherapy.

Identify the profile of people with colostomy registered in the Attention Program of people with colostomy of Paraná.

Comparison of the quality of life of the patients with colorectal neoplasia with and without intestinal ostomy.

Exploration of the differences of gender on the stress and confrontation strategies in people with colorectal neoplasia.

Evaluation of the quality of life of people with colorectal neoplasia.

Refinement of the validity of the matter of an auditing tool that defines and measures the best practices in nursing to the patient with colorectal cancer and identify fields to the development of this field.

Refinement of the validity of the matter of an auditing tool that defines and measures the best practices in nursing to the patient with colorectal cancer and identify fields to the development of this field.

Multidisciplinary consensus of experts, using the Delphi technique, with the goal of defining core treatment strategies and development of a structured European auditing, to improve the quality of the care to all patients with cancer in the colon and rectum.

Multidisciplinary consensus of experts, using the Delphi technique, with the goal of defining core treatment strategies and development of a structured European auditing, to improve the quality of the care to all patients with cancer in the colon and rectum.

MAHON ET AL. 2000

Establishment of strategies of screening to detect early colorectal neoplasia, to implement educational activities and clinical protocols.

MAZANEC SR, FLOCKE

SA, DALY BJ. 2015

Investigation about the feelings and habits of life of patients with colorectal neoplasia and their relatives, to subsidize posterior interventions of the nursing team.

LIN WL, ET AL. 2014

Evaluation of the satisfaction of the patients with colorectal neoplasia in relation to the telephone advising service realized by nurses.

JEFFORD M. ET AL. 2013 Evaluation of the impact of an educative intervention realized from on-site visits and phone calls.

GREEN BB. 2010

Determination of the effectiveness and cost-effectiveness relation of the phased increases in support systems to increase the colorectal neoplasia tracking and the follow-up after a positive screening test.

JESSICA T. DEFRANK, 2007

Evaluation of the perception of the body image of people with colorectal neoplasia to subsidize the psychological needs of the care of nursing of those people. 
the quality of life of those people. The Nursing acts intervening at different stages of this process, taking care to improve the quality of life and self-care [18].

Four studies brought evaluations of the satisfaction of patients in relation to the health services, their perceptions about the relationship with the professionals and the monitoring over phone made by nurses to the patients that are not in outpatient/hospital treatment anymore [19]-[22]. The satisfaction of the patient is shown as an indicator of the quality of the health assistance performed by the institution and receives positive influence of factors like the absence of lucrative intention of the hospital, localization in urban environment, teaching hospital, more numbers of nurses, lower readmission and mortality perioperative rates [23].

As it was said, the nurses have an essential role on the health services relative to the management of the services and the care of the nursing team, studies about the evaluation of the satisfaction in these cares are relevant to direct and propose changes in a way to strengthen the reach of the results [24].

One study evaluated the knowledge of the professionals about the risks and benefits of the weight management in patients with colorectal neoplasia. Studies of systematic review with meta-analysis including data of countries from North America, Europe and Oceania reinforce the association between the weight gain in adult, young or advanced ages, to both genders on the development of the colorectal cancer [25].

Four studies traced the profile of the patients, being the investigation about the physical, psychological and social needs of this clientele, in addition to the feeling and life habits of patients with colorectal neoplasia and their relatives related to the stages experienced during the diagnostic and treatment, with the objective of supporting subsequent interventions of the nursing team [26]-[29].

Unfavorable socioeconomic characteristics like low income, non-ideal residence, exposure to atmospheric pollution in heavily industrialized fields, normally are connected to risky behavior like unbalanced diets, use of alcohol and tobacco, sedentary lifestyle. Beyond that, these populations are normally inserted in the informal labor market or in unhealthy conditions, which ends bringing higher occupational risks (accidents, professional diseases) and precarious home conditions. Associated to all these aggravating circumstances, there is also the difficulty to access health services. All of those factors increase the risk of developing diseases and makes it difficult the detection and appropriate treatment of them [30]-[32].

One study evaluated the influence of the socio-cultural and gender factors and their extension at the decision about the tracking of colorectal neoplasia [33]. The tracking program, or patient navigation program, seems to have a positive effect over time by accelerating the diagnostic after four months of follow-up, being, therefore, an important strategy in the early care of this type of cancer [34].

One study developed a strategy of screening to detect an early colorectal cancer for subsequent implementation of clinical protocols and educative activities [35]. And five studies approached an evaluation of measure instruments, assistance plans and care strategies to this clientele. One study even compared two different surgical approaches in relation to the costs of the nursing assistance to the bearer of colorectal cancer [36]-[41]. The preparation and implementation of these protocols involves the use of high quality scientific evidence, as well as the use of pointers to evaluate them, which involve the complete diagnostic of the colorectal neoplasia, determination of the carcinoembryonic antigen (CEA) serum in the post-operative period, lymph nodes exams, daily cleanse of the operative wound, reference to the oncologist, use of chemotherapy adjuvants after 8 weeks of the surgery and evaluation of the obstruction from the colonoscopy. Beyond that, the evaluation of the hospital costs forms a factor to determine the patient satisfaction [42] [43].

Consequently, studies that approach assistance technologies used in the care to the people with colorectal neoplasia were also identified. They are demonstrated in Table 2.

The assistance technologies involve "the construction of a self-technical-scientific know-how and procedures and techniques used for the care" [2], therefore, it involves an application of an intervention on the other by part of the nursing team.

Few studies brought as research results the use of assistance care technologies in nursing, yet, showed new approaches of nursing interventions. One of them approaches an intervention that make records of the patients that must be tracked, with the goal to ensure the referral process to the treatment and preparation of the patients to a complete the diagnostic test [44].

A second study describes the use and benefits of the acupuncture in the recovery of patients with colorectal neoplasia submitted to surgical treatment [45]. And the last study found is about the nursing assistance made by professionals that received specific treatment about time commitment, maximum number of clients for each nurse and approaching to the patient with colorectal neoplasia in psychological suffering during the treatment 
Table 2. Distribution of the studies in relation to the assistance technologies used in the care of the people with colorectal neoplasia.

\begin{tabular}{|c|c|}
\hline ID & Used Technology \\
\hline GREEN ET AL. 2010 & $\begin{array}{l}\text { Intervention of nursing that makes records of the patients that must be tracked, ensure the process of referral } \\
\text { of the treatment and prepare the patients to complete the diagnostic test. }\end{array}$ \\
\hline CHAO, H ET AL. 2013 & $\begin{array}{l}\text { Use of acupuncture on the recovery of patients with colorectal neoplasia that were submitted to surgical } \\
\text { treatment. }\end{array}$ \\
\hline WAGNER ET AL.,y 2014 & $\begin{array}{l}\text { Assistance of differentiated nursing made by professionals that received specific training about time } \\
\text { commitment, maximum number of clients to each nurse and an approach to the patient with colorectal } \\
\text { neoplasia in psychological suffering during the treatment. }\end{array}$ \\
\hline $\begin{array}{l}\text { SARAH K. } \\
\text { ROSENBLOOM, } 2007\end{array}$ & $\begin{array}{l}\text { Execution of periodic evaluations of quality of life of the patients with colorectal neoplasia, followed by } \\
\text { structured interviews to advice and discussion about the clinical condition of the client. }\end{array}$ \\
\hline
\end{tabular}

and the benefits of a different approach [46].

This amount of results shows a gap in the literature in what refers to the study of nursing intervention, with high level of evidence, being this type of research fundamental to the progress of science in this job, subsidizing, with a larger safety, the nursing techniques on the care to the people with colorectal neoplasia [47]. This way, it's important to highlight the importance of the promotion of the nursing interventions, to supply a wide array of even larger options to professionals aiming to obtain the appropriate technology, in other words, the one that attend to the needs and expectations of a determined population, bearing in mind that the nursing techniques and technologies that form the nursing know-how used by the ones that execute it to the improvement of their praxis [48].

As it follows, there are the educational technologies used in the care to the people with colorectal neoplasia, which are shown in Table 3.

Educational technology used in the care refers to a "systematic set of knowledge that makes it possible the planning, execution, control and follow-up of an educational process" [2], where it is needed an educator/facilitator and the pupil that in nursing corresponds respectively to the nurse and the clientele. The present study identified three studies with educational technologies as results of the nursing range of activity.

Two of them implemented and evaluated education programs and evaluated the impact of this intervention on patients with colorectal cancer in of after treatment [21]-[49]. A third study after evaluating the quality of life of the clients conducted counseling and discussion about their clinical condition [50].

A study made in Australia evaluated the quality of the communication skills of the nurse in his interaction with the clients highlighting the clinical knowledge, the need to establish a close and trustworthy relationship with the client, have the sensibility to identify the needs of the client and readiness to listen to his information, in addition to the capacity to adapt the form of supplying information to each client individually, are characteristics considered fundamental so that the nurse can develop a good role as a health educator [51].

The needs of self-care of the patient with colorectal neoplasia are various, especially after the surgical approach of intestinal resection. The nursing has been building methods of teaching to the patient so he can comprehend the disease and the precautions needed during the treatment, like the manipulation of the ostomy pouch, that includes traditional instructions, use of DVD's, interaction group and feedback over phone [52]-[54].

From what has been exposed, it's important to highlight that the use of the nursing know-how as technology has an emancipating nature to the science and the job, used as an instrument to overcome obstacles and restrictions that submit the labor process of the nurse. So, the construction of self-knowledge of the nursing helps to build the critical conscience of the nurses, and the population, in the pursuit for freedom and autonomy of nursing to supply the specific cares for the people with colorectal neoplasia [48].

\section{Conclusion}

From Nietzsche's theoretical reference, it was possible to identify the technologies used by the nurses in the care of people with colorectal neoplasia, being most of them classified as management technology (86.20\%), followed by the assistance technology (20.68\%) and lastly, educational technology (10.34\%). Studies published in the last five years have predominated (62.06\%), in international territory (82.75\%) and with level of evidence IV (44.82\%). 
Table 3. Distribution of the studies in relation to the educational technologies used in the care to the people with colorectal neoplasia.

\begin{tabular}{|c|c|}
\hline ID & Used technology \\
\hline G. KNOWLES ET AL. 2008 & $\begin{array}{l}\text { Implementation of an education program based on the evidences and evaluation of the impact of these } \\
\text { interventions from the perception of changes in the professional experience of the nurses. }\end{array}$ \\
\hline JEFFORD M. ET AL. 2013 & $\begin{array}{l}\text { Preparation, implementation and evaluation of an individualized educative plan to the patients after the } \\
\text { treatment of colorectal neoplasia. }\end{array}$ \\
\hline
\end{tabular}

Currently, it's possible to see an increase in nursing scientific production about care technologies for people with colorectal neoplasia, but, most of the studies have limited themselves to describe a few important aspects to the managing activity of nursing, highlighting that the know-how, as an emancipatory technology, remains at the exploratory stage of the aspects involved in the health assistance of these individuals.

Therefore, it becomes evident that the scientific gap in the productions with high level of evidence forms the self-sufficient knowledge about the care and nursing interventions that may subsidize the professional technique more efficiently in relation to the safety and positive results on the population at issue.

Thus, this study shows itself as a type of technology available to subsidize the knowledge of the nurses related to the actual overview of the publications about the care technologies for people with colorectal neoplasia, as well as provides contributions to the advance of nursing science using as theoretical background a nurse with $\mathrm{PhD}$ at the theme, emphasizing and expanding the technological know-how of this job.

\section{References}

[1] Salvador, P.T.C.O., Oliveira, R.K.M., Costa, T.D., Santos, V.E.P. and Tourinho, F.S.V. (2012) Tecnologia e inovação para o cuidado em enfermagem. Revista de Enfermagem, 20, 111-117.

[2] Nietsche, E.A., Backes, V.M.S., Colomé, C.L.M., Ceratti, R.N. and Ferraz, F. (2005)Tecnologias educacionais, assistenciais e gerenciais: uma reflexão a partir da concepção dos docentes de enfermagem. Revista Latino-Americana de Enfermagem, 13, 344-352. http://dx.doi.org/10.1590/S0104-11692005000300009

[3] Silva, R.C. and Ferreira, M.A. (2014) Tecnologia no cuidado de enfermagem: Uma análise a partir do marco conceitual da Enfermagem Fundamental. Revista Brasileira de Enfermagem, 67, 111-118.

[4] Instituto Nacional de Câncer José Alencar Gomes da Silva (2014) Coordenação de Prevenção e Vigilância Estimativa 2014: Incidência de Câncer no Brasil/Instituto Nacional de Câncer José Alencar Gomes da Silva, Coordenação de Prevenção e Vigilância. INCA, Rio de Janeiro.

[5] Zandonai, A.P., Sawada, N.O. and Sonobi, H.M. (2012) Os fatores de risco alimentares para o câncer colorretal relacionado ao consumo de carnes. Revista da Escola de Enfermagem da USP, 46, 234-239. http://dx.doi.org/10.1590/S0080-62342012000100031

[6] Lee, J. (2015) Association between Physical Fitness, Quality of Life, and Depression in Stage II-III Colorectal Cancer Survivors. Supportive Care in Cancer, 23, 2569-2577. http://dx.doi.org/10.1007/s00520-015-2615-y

[7] Pereira, A.P.S., Cesarino, C.B., Martins, M.R.I., Pinto, M.H. and Netinho, J.G. (2012) Associação dos fatores sociodemográficos e clínicos à qualidade de vida dos estomizados. Revista Latino-Americana de Enfermagem, 20, 1-8.

[8] Justino, E.T., Mantovani, M.F., Kalinke, L.P., Ulbrich, E.M., Moreira, R.C. and Abini, L. (2014) A trajetória do câncer contada pela enfermeira: Momentos de revelação, adaptação e vivência da cura. Escola Anna Nery, 18, 41-46.

[9] Moraes, J.T., Amaral, C.F.S., Borges, E.L., Ribeiro, M.S. and Guimarães, E.A.A. (2014) Serviços de atenção ao estomizado: Análise diagnóstica no Estado de Minas Gerais, Brasil. Cadernos Saúde Coletiva, 22, 101-108. http://dx.doi.org/10.1590/1414-462X201400010015

[10] Whittemore, R. and Knafl, K. (2005) The Integrative Review: Update Methodology. Journal of Advanced Nursing, 52, 546-553. http://dx.doi.org/10.1111/j.1365-2648.2005.03621.x

[11] Ganong, L.H. (1987) Integrative Review of Nursing Research. Research in Nursing \& Health, 10, 1-11. http://dx.doi.org/10.1002/nur.4770100103

[12] Lillemoen, L. and Pedersen, R. (2012) Ethical Challenges and How to Develop Ethics Support in Primary Health Care. Nursing Ethics, 20, 96-108.

[13] Karino, M.E. and Felli, V.E.A. (2012) Enfermagem baseada em evidências: Avanços e inovações em revisões sistemáticas. Ciência, Cuidado e Saúde, 11, 11-15. http://dx.doi.org/10.4025/cienccuidsaude.v11i5.17048

[14] O’Mara, A.M. and Denicorff A.M. (2010) Health Related Quality of Life in NCI-Sponsored Cancer Treatment Trials. 
Seminars in Oncology Nursing, 26, 68-78. http://dx.doi.org/10.1016/j.soncn.2009.11.009

[15] Buetto, L.S. and Zago, M.M.F. (2015) Significados da qualidade de vida no contexto da quimioterapia pelo paciente com câncer colorretal. Revista Latino-Americana de Enfermagem, 23, 427-434. http://dx.doi.org/10.1590/0104-1169.0455.2572

[16] Michelone, A.P.C. and Santos V.L.C.G. (2004) Qualidade de vida de adultos com câncer colorretal com e sem ostomia. Revista Latino-Americana de Enfermagem, 12, 875-883. http://dx.doi.org/10.1590/S0104-11692004000600005

[17] Chaves, P.L., Pinto, M.I. and Gorini, C. (2011) Qualidade de vida do paciente com câncer colorretal em quimioterapia ambulatorial. Revista Gaúcha de Enfermagem, 32, 767-773.

[18] Lai, C.K.Y., Leung, D.D.M., Kwong, E.W.Y. and Lee, R.L.P. (2015) Factors Associated with the Quality of Life of Nursing Home Residents in Hong Kong. International Nursing Review, 62, 120-129. http://dx.doi.org/10.1111/inr.12152

[19] Beaver K., Wilson C., Procter D., Sheridan J., Towers G., Heath J. (2011) Colorectal Cancer follow-Up: Patient Satisfaction and Amenability to Telephone after Care. European Journal of Oncology Nursing, 15, 23-30. http://dx.doi.org/10.1016/j.ejon.2010.05.006

[20] Lin, W.L., Sun, J.L., Chang, S.C., Wu, P.H., Tsai, T.C. and Huang, W.T. (2014) Development and Application of Telephone Counseling Services for Care of Patients with Colorectal Cancer. Asian Pacific Journal of Cancer Prevention, 15, 969-973. http://dx.doi.org/10.7314/APJCP.2014.15.2.969

[21] Jefford, M., Aranda, S., Gough, K., Lotfi-Jam, K., Butow, P. and Krishnasamy, M. (2013) Evaluating a Nurse-Led Survivorship Care Package (Survivor Care) for Bowel Cancer Survivors: Study Protocol for a Randomized Controlled Trial. Trials, 14, 260. http://dx.doi.org/10.1186/1745-6215-14-260

[22] McCarthy, B. (2014) Patients' Perceptions of How Healthcare Providers Communicate with Them and Their Families Following a Diagnosis of Colorectal Cancer and Undergoing Chemotherapy Treatment. European Journal of Oncology Nursing, 18, 452-458. http://dx.doi.org/10.1016/j.ejon.2014.05.004

[23] Tsai, T.C., Orav E.J. and Jha, A.K. (2015) Patient Satisfaction and Quality of Surgical Care in US Hospitals. Annals of Surgery, 261, 2-8. http://dx.doi.org/10.1097/SLA.0000000000000765

[24] Sinclair, A. and Whitford, A. (2015) Effects of Participation and Collaboration on Perceived Effectiveness of Core Public Health Functions. American Journal of Public Health, 105, 1638-1645. http://dx.doi.org/10.2105/AJPH.2015.302586

[25] Schlesinger, S., Lieb, W., Koch, M., Fedirko, V., Dahm, C.C., Pischon, T. and Nöthlings, U. (2015) Body Weight Gain and Risk of Colorectal. Obesity Reviews, 16, 607-619. http://dx.doi.org/10.1111/obr.12286

[26] Sierko, E., Werpachowska, M.T. and Wojtukiewicz, M.Z. (2011) Psychological, Physical, and Social Situation of Polish Patients with Colorectal Cancer Undergoing First-Line Palliative Chemotherapy. Oncology Nursing Forum, 38, 253-259. http://dx.doi.org/10.1188/11.ONF.E253-E259

[27] Mazanec, S.R., Flocke S.A. and Daly, B.J. (2015) Health Behaviors in Family Members of Patients Completing Cancer Treatment. Oncology Nursing Forum, 42, 54-62. http://dx.doi.org/10.1188/15.ONF.54-62

[28] Violin, M.R., Mathias, T.A.F. and Uchimura, T.T. (2008) Perfil de clientes colostomizados inscritos em programa de atenção aos estomizados. Revista Eletrônica de Enfermagem, 10, 924-932.

[29] Jonsson, C.A., Stenberg, A. and Frisman, G.H. (2010) The Lived Experience of the Early Postoperative Period after. European Journal of Cancer Care, 20, 248-256. http://dx.doi.org/10.1111/j.1365-2354.2009.01168.x

[30] Sobrinho, F.M., Silva, Y.C., Abreu, M.N.S., Pereira, S.C.L. and Dias Jr., C.S. (2014) Fatores determinantes da insegurança alimentar e nutricional: estudo realizado em Restaurantes Populares de Belo Horizonte, Minas Gerais, Brasil. Ciência \& Saúde Coletiva, 19, 1601-1611. http://dx.doi.org/10.1590/1413-81232014195.18022013

[31] Meireles, A.L., Xavier, C.C., Sales, A.D.F., Abreu, M.N.S., Malta, D.C. and Caiaffa, W.T. (2013) Perfil alimentar de adolescentes e adultos jovens em Belo Horizonte segundo perfil antropométrico e contexto de moradia. Revista Médica de Minas Gerais, 23, 12-19.

[32] Teixeira, J.A.C. and Correia, A.R. (2002) Fragilidade social e psicologia da saúde. Um exemplo de influências do contexto sobre a saúde. Análise Psicológica, 20, 359-365.

[33] Ticona, B.S.B., Santos, M.E.M. and Siqueira, C.A.L. (2015) Diferencias de género en la percepción de estrés y estrategias de afrontamiento en pacientes con cáncer colorrectal que reciben quimioterapia. Aquichan, 15, 9-20. http://dx.doi.org/10.5294/aqui.2015.15.1.2

[34] Lee, J.H., Fulp, W., Wells, K.J., Meade, C.D., Calcano, E. and Roetzheim, R. (2014) Effect of Patient Navigation on Time to Diagnostic Resolution among Patients with Colorectal Cancer-Related Abnormalities. Journal of Cancer Education, 29, 144-150. http://dx.doi.org/10.1007/s13187-013-0561-2

[35] Mahon, S.M., Williams, M.T. and Spies, M.A. (2000) Screening for Second Cancers and Osteoporosis in Long-Term 
Survivors. Cancer Practice, 8, 282-290. http://dx.doi.org/10.1046/j.1523-5394.2000.86008.x

[36] Faul, L.A., Rivers, B., Shibata, D., Townsend, I., Cabrera, P. and Quinn, G.P. (2012) Survivorship Care Planning in Colorectal Cancer: Feedback from Survivors \& Providers. Journal of Psychosocial Oncology, 30, 198-216. http://dx.doi.org/10.1080/07347332.2011.651260

[37] Grocott, P., Richardson, A., Ambaum, B., Kearney, N. and Redmond, K. (2001) Nursingin Colorectal Cancer Initiative Theauditphase. Part 1. Development of Theaudit Tool. European Journal of Oncology Nursing, 5, 100-111. http://dx.doi.org/10.1054/ejon.2001.0141

[38] Grocott, P., Richardson, A., Ambaum, B., Kearney, N. and Redmond, K. (2001) Nursingin Colorectal Cancer Initiative: the Audit Phase. Part 2. Content Validity of the Audit Tool Andimplications of the Standards Set for Clinical Practice. European Journal of Oncology Nursing, 5, 165-173. http://dx.doi.org/10.1054/ejon.2001.0140

[39] Velde, C.J.H., Aristei, C., Boelens, P.G., Beets-Tan, R.G.H., Blomqvist, L. and Borras, J.M. (2013) EURECCA Colorectal: Multidisciplinary Mission Statement on Better Care for Patients with Colon and Rectal Cancer in Europe. European Journal of Cancer, 49, 2784-2790. http://dx.doi.org/10.1016/j.ejca.2013.04.032

[40] Velde, C.J.H., Boelens, P.G., Borras, J.M., Coebergh, J., Cervantes, A., Blomqvist, L. and Beets-Tan, R.G.H. (2014) EURECCA Colorectal: Multidisciplinary Management: European Consensus Conference Colon \& Rectum. European Journal of Cancer, 50, 1.e1-1.e34. http://dx.doi.org/10.1016/j.ejca.2013.06.048

[41] Norwood, M.G.A., Stephens, J.H. and Hewett, P.J. (2011) The Nursing and Financial Implications of Laparoscopic Colorectal Surgery: Data from a Randomized Controlled Trial. Colorectal Disease, 13, 1303-1307. http://dx.doi.org/10.1111/j.1463-1318.2010.02446.x

[42] Coca, C., Larrinoa, I.F., Serrano, R. and García-Llana, H. (2015) The Impact of Specialty Practice. Nursing Care on Health-Related Quality of Life in Persons with Ostomies. Journal of Wound Ostomy \& Continence Nursing, 42, 257263. http://dx.doi.org/10.1097/WON.0000000000000126

[43] Jackson, G.L., Zullig, L.L., Zafar, S.Y., Powell, A.A., Ordin, D.L. and Gellad, Z.F. (2013) Using NCCN Clinical Practice Guidelines in Oncology to Measure the Quality of Colorectal Cancer Care in the Veterans Health Administration. Journal of the National Comprehensive Cancer Network, 11, 431-441.

[44] Green, B.B., Wang, C.Y., Horner, K., Catz, S., Meenane, R.T. and Vernon, S.W. (2010) Systems of Support to Increase Colorectal Cancer Screening and Follow-Up Rates (SOS): Design, Challenges, and Baseline Characteristics of Trial Participants. Contemporary Clinical Trials, 31, 589-603. http://dx.doi.org/10.1016/j.cct.2010.07.012

[45] Chao, H., Miao, S., Liu, P., Lee, H.H., Chen, Y. and Yao, Y. (2013) The Beneficial Effect of ST-36 (Zusanli) Acupressure on Postoperative Gastrointestinal Function in Patients With Colorectal Cancer. Oncology Nursing Forum, 40, 61-68. http://dx.doi.org/10.1188/13.ONF.E61-E68

[46] Wagner, E.H., Ludman, E.J., Bowles, E.J.A., Penfold, R., Reid, R.J. and Rutter, C.M. (2014) Nurse Navigators in Early Cancer Care: A Randomized, Controlled Trial. American Society of Clinical Oncology, 32, 12-15. http://dx.doi.org/10.1200/JCO.2013.51.7359

[47] Karino, M.E. and Felli, V.E.A. (2012) Enfermagem baseada em evidências: avanços e inovações em revisões sistemáticas. Ciência, Cuidado e Saúde, 11, 11-15. http://dx.doi.org/10.4025/cienccuidsaude.v11i5.17048

[48] Nietsche, E.A. (1961) Caminho Teórico. Nova Cultural, São Paulo.

[49] Knowles, G., Hutchison, C., Smith, G., Philp, I.D., McCormick, K. and Preston, E. (2008) Implementation and Evalution of a Pilot Education Programme in Colorectal Cancer Managnement for Nurses in Scotlan. Nurse Education Today, 28, 15-23. http://dx.doi.org/10.1016/j.nedt.2007.02.002

[50] Rosenbloom, S.K., Victorson, D.E., Hahn, E.A., Peterman, A.H. and Cella, D. (2007) Assessment Is Not Enough: A Randomized Controlled Trial of the Effects of HRQL Assessment on Quality of Life and Satisfaction in Oncology Clinical Practice. Psycho-Oncology, 16, 1069-1079. http://dx.doi.org/10.1002/pon.1184

[51] O’Hagan, S., Manias, E., Elder, C., Pill, J., Woodward-Kron, R. and McNamara, T. (2014) What Counts as Effective Communication in Nursing? Evidence from Nurse Educators' and Clinicians' Feedback on Nurse Interactions with Simulated Patients. Journal of Advanced Nursing, 70, 1344-1355. http://dx.doi.org/10.1111/jan.12296

[52] Karalabut, H.K., Dinç, L. and Karadag, A. (2014) Effects of Planned Group Interactions on the Social Adaptation of Individuals with an Intestinal Stoma: A Quantitative Study. Journal of Clinical Nursing, 23, 2800-2813. http://dx.doi.org/10.1111/jocn.12541

[53] Zhang, J.E., Wong, F.K., You, L.M. and Zheng, M.C. (2011) A Qualitative Study Exploring the Nurse Telephone Follow-Up of Patients Returning Home with a Colostomy. Journal of Clinical Nursing, 21, 1407-1415. http://dx.doi.org/10.1111/j.1365-2702.2011.03824.x

[54] Crawford, D., Texter, T., Hurt, K., Vanaelst, R., Glaza, L. and Laan, K.J.V. (2012) Traditional Nurse Instruction versus 2 Session Nurse Instruction Plus DVD for Teaching Ostomy Care: A Multisite Randomized Controlled Trial. Journal of Wound, Ostomy, and Continence Nursing, 5, 529-537. http://dx.doi.org/10.1097/WON.0b013e3182659ca3 


\section{Submit or recommend next manuscript to SCIRP and we will provide best service for you:}

Accepting pre-submission inquiries through Email, Facebook, LinkedIn, Twitter, etc.

A wide selection of journals (inclusive of 9 subjects, more than 200 journals)

Providing 24-hour high-quality service

User-friendly online submission system

Fair and swift peer-review system

Efficient typesetting and proofreading procedure

Display of the result of downloads and visits, as well as the number of cited articles

Maximum dissemination of your research work

Submit your manuscript at: http://papersubmission.scirp.org/ 